\title{
Coenzime Q10. Comparative Study Active Substance versus Pharmaceuticals Products
}

\author{
CRISTINA BUCIUMAN, ELEONORA MARIAN², BOGDAN TITA3*, TUNDE J URCA2, ADRIANA CHIS ${ }^{4}$, LAURA VICAS ${ }^{1,2}$ \\ ${ }^{1}$ Carol Davila University of Medicine and Pharmacy, Faculty of Pharmacy, 6 Traian Vuia Str., 020956, Bucharest, Romania \\ 2University of Oradea, Faculty of Medicine and Pharmacy, 29 Nicolae Jiga Str., 410028, Oradea, Romania \\ ${ }^{3}$ Vasile Goldis Western University of Arad, Faculty of Pharmacy, Department of Pharmaceutical Sciences, 86 L. Rebreanu Str., \\ 300041, Arad, Romania \\ ${ }^{4}$ Lucian Blaga University, Faculty of Medicine, 10 Victoriei Blvd, 550024, Sibiu,Romania
}

\begin{abstract}
Coenzyme Q10 is a molecule which shows promising properties in the prevention and treatment of different disorders. It is mostly found in dietary supplements together with different excipients and other lipophilic vitamins that can influence the release profile of the active substance. This influence is due to the possible interaction of the active substance with the excipients present in the drug composition. In this regard, this paper presents a comparative study between coenzyme Q10-active substance and three of the corresponding pharmaceutical products: P1, P2 and P3. The four compounds were characterized simultaneously by thermal analysis, FT-IR spectroscopy and X-ray powder diffraction patterns.
\end{abstract}

Keywords: coenzyme Q10, thermal analysis, FT-IR spectroscopy, X-ray

Coenzyme $\mathrm{Q} 10$ is a lipidic molecule, with a significant role in the production of ATP at mitochondrial level. It was discovered by professor F. Crane and fellows at the research Centre of the Wisconsin-Madison Enzyme Institute University in 1957. A year later, dr. K. Folkers and colleagues at Merck identified its chemical structure 2,3 dimethoxy5methyl-6dicaprenyl-1, benzoquinone. In 1961 Mitchell proposes for the first time its mechanism of functioning through electron transportation chain for which he will receive the Nobel Prize in 1978. In 1972 Gian Paolo Littarru and Karl Folkers demonstrate separately coenzyme Q10 efficiency in heart failure.<smiles>CCCCCC(C)=CC=CC(C)C</smiles>

Fig. 1. Chemical structure of coenzyme Q10

Coenzyme Q10 has a high molecular weight, it is highly lipophile, with low water solubility and good permeability, which enables its classification in BCS class II substances. Following these characteristics, we have identified numerous attempts to increase its solubility and consequently its bioavailability through different ways.

In Romania coenzyme Q10 is found in dietary supplements mostly soft gelatin capsules (containing a mixture of coenzyme Q10 and lipophilic vitamins dissolved or dispersed in lipophilic media), but also tablets and even jelly. As sources of ubiquinone we can mention: own synthesis, food sources: sardines, pork, beef, olive oil, broccoli, butter [1].

Thermal analysis is a method currently used for the characterization of pharmaceutical products in their development during pilot level research. The information gathered is useful for obtaining a final, optimized pharmaceutical form and to estimate the behavior of products which are in the development phase at different stages, for example stability testes and their behavior when exposed to accelerated environment conditions.
Thermal analysis gives insight into the physical characteristics of a pharmaceutical product (purity, polymorphism, thermal stability, compatibility, etc.). There have been numerous studies on the interaction of active substance and excipients [2-4].

By using thermogravimetry, the mass of a sample is measured constantly, according to temperature, while it is heated or cooled down with a controlled rate, or maintained at a certain temperature for a period of time. The recording obtained is the thermogravimetric curve.

This method is mentioned in literature as useful for the characterization of some Coenzyme Q10- $\beta$-cyclodextrins complexes modified with polyamide for the growth of solubility [5], but also for other active ingredients [6,7].

Differential scanning calorimetry (DSC) is a preferred technique used in the measurement of the thermic properties of a substance in order to establish a connection between temperature and the physical properties of the substance; it is the only method to directly determine the enthalpy of the process.

The differential scanning calorimeter is a device that measures the ways in which the physical properties of the sample are modified during the process of heating the sample during a specific time. As the temperature becomes higher, the heat absorbed by the sample is measured, according to the difference of temperature between the sample tested and the reference sample. There are two kinds of devices used to record these phenomena: with heat flow (it measures the difference between sample and reference) and with caloric power compensation (it transforms the difference in temperature in caloric power need to compensate the thermic equilibrium between the reference and the sample). Although in both types the signal measured is the temperature difference recorded by the sensors, the differential heat flow from the oven to the sample and reference is measured using different ways [8].

DSC has numerous applications is many fields among which we mention the determination of active substance-

\footnotetext{
*email: bogdantita@yahoo.com
} 
excipient interaction in oral solid dosage forms. Yuan et. $\mathrm{Al}$, has developed a method to determine the performance of active substances in lipidic nanospheres encapsulation. Other applications are also available [9-12] .

Both thermal analysis methods have been used to characterize different improved pharmaceutical forms of coenzyme Q10, for example micronized CoQ10 powder to the nanometer level by the supercritical solution (RESS) process [13].

For a more complete analysis and interpretation of thermic analysis Fourier transformed infrared spectroscopy (FT-IR) and X-ray diffraction can be used.

These are methods can be used to get an insight into the behavior of lipid structures. While FT-IR is sensitively providing structure information at the molecular level from different parts of the molecules, X-ray scattering can provide data on long-range order phenomena and on fatty acid chain packing pattern, as it did in other papers mentioned in literature [14].

\section{Experimental part}

Materials and methods

The substances examined by thermal analysis, FT-IR spectroscopy and X-ray analysis were coenzyme Q10 active substance (CQ10-AS) and three pharmaceutical products (P1, P2, P3)

The active substance was obtained from XinchangPharma, China, lot: 1508108, as pure compound, able to be used for medical purposes.

The pharmaceuticals (drugs) were commercial products, containing different excipients.

\section{Thermal analysis}

The TG/DTG and DTA curves were recorded using a Netzsch-STA 449 TG/DTA instrument in the temperature range $20-1000{ }^{\circ} \mathrm{C}$, under a dynamic atmosphere of nitrogen $\left(20 \mathrm{~mL} \cdot \mathrm{min}^{-1}\right)$ and at a heating rate $(\beta) 10^{\circ} \mathrm{C} \cdot \mathrm{min}^{-1}$, using platinum crucibles and weighed $\mathrm{H} \approx 20 \mathrm{mg}$ of samples.

Fourier transformed infrared spectroscopy (FT-IR) and Xray diffraction

FT-IR spectra were recorded on a Shimadzu Prestige21 apparatus using $\mathrm{KBr}$ discs in the range $4000-400 \mathrm{~cm}^{-1}$. X-ray diffraction patterns (XRPD) were obtained with a Rigaku Ultima IV diffractometer ( $\mathrm{Cu}_{\mathrm{k \alpha}}$ radiation).

\section{Results and discussions}

\section{Thermal analysis}

The thermal curves TG, DTG and DSC of the studied compounds are shown in figures 2 to 5 .

Their main features are included in table 1.

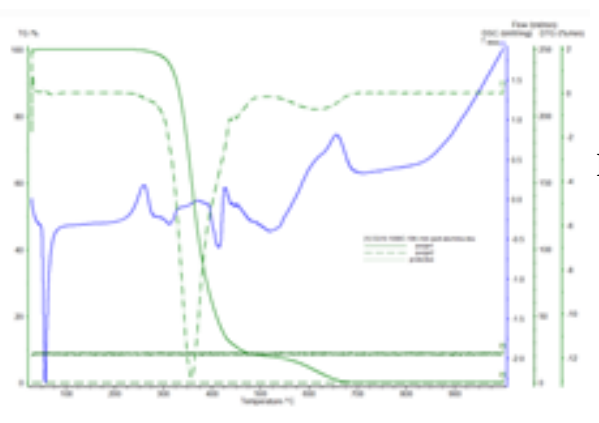

Fig. 2 TG/DTG and

DSC curves for CQ10-AS

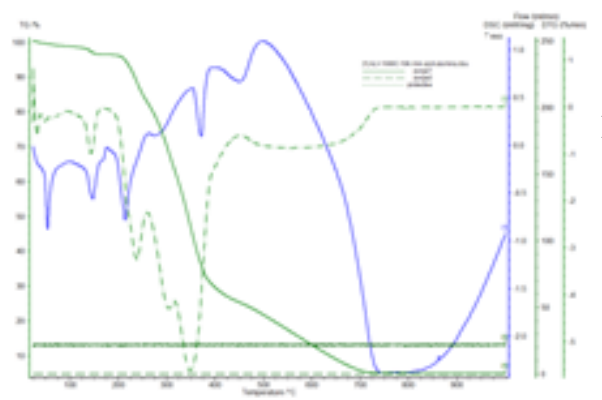

Fig. 3 TG/DTG and DSC curves for P1

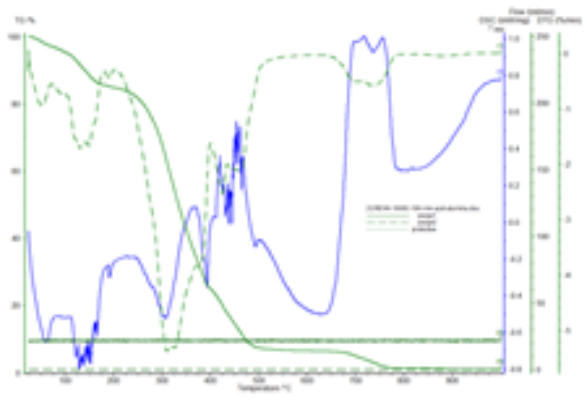

Fig. 4 TG/DTG and DSC curves for P2

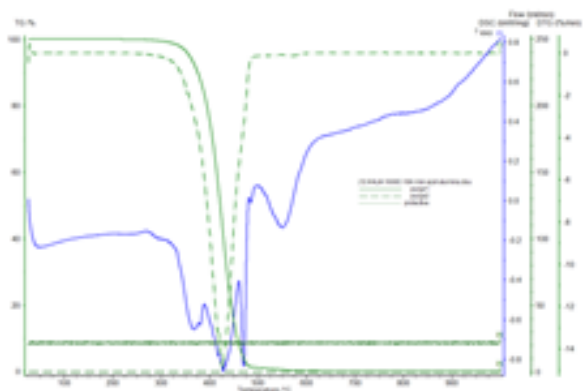

Fig. 5 TG/DTG and DSC curves for P3

According to the thermal curves and thermoanalytical data from table 1, the thermal behavior of the coenzyme Q10 (active substance) and the P3 pharmaceutical product is about the same and simpler than the relatively more complex relapsed pharmaceutical products P2 and P1. The relatively more complex behavior of the two mentioned pharmaceutical compounds is found by the

\begin{tabular}{|c|c|c|c|c|}
\hline Sample & $\begin{array}{c}\text { Range of mass } \\
\text { loss, }{ }^{\circ} \mathrm{C}\end{array}$ & $\begin{array}{c}\text { Maximum of } \\
\text { DTG, }{ }^{\circ} \mathrm{C}\end{array}$ & Maximum of DSC, ${ }^{\circ} \mathrm{C}$ & Mass loss, $\Delta \mathrm{m} \%$ \\
\hline \multirow{4}{*}{ Q10 } & $55-91$ & - & 59.3 endo & fusion \\
& $215-278$ & - & 255.6 exo & physics transformation \\
& $278-515$ & 354.8 & 313.7 endo;413.3 endo; 514.8 endo & 91.10 \\
& $515-700$ & 622.2 & 653.3 exo & 8.90 \\
\hline \multirow{4}{*}{ P1 } & $34-100$ & 55.6 & 55.6 & fusion; 1,65 \\
& $100-167$ & 143.0 & 145.2 & 2.42 \\
& $167-259$ & 237.0 & 175.0 & 15.59 \\
& $259-400$ & $300.0 ; 348.1$ & $276.3 ; 374.2$ & 53.07 \\
& $400-737$ & 566.7 & 448.2 & 27.27 \\
\hline \multirow{5}{*}{ P2 } & $25-82$ & 52.3 & 55,6 & fusion $; 4,40$ \\
& $82-200$ & 131.1 & 131,1 & 10.98 \\
& $200-400$ & 317.8 & $307.4 ; 391.9$ & 60.44 \\
& $400-544$ & 424.4 & 436.7 & 6.14 \\
\hline \multirow{2}{*}{ P3 } & $544-781$ & 722.2 & 728.1 & fusion \\
& $25-76$ & - & 50.0 & 98.33 \\
& $285-494$ & 428.2 & $368.1 ; 428.2 ; 473.3$ & 1.67 \\
\hline
\end{tabular}

Table 1

CHARACTERISTICS OF

THE THERMAL

BEHAVIOR OF THE STUDIED COMPOUNDS 
presence of additional decomposition steps compared to the active substance. These steps are particularly emphasized on the DTG and DSC curves, by the corresponding peaks due to the presence of excipients or their possible interaction with the active substance.

The active substance (CQ10) and the P3 pharmaceutical product have high thermal stability $\left(\approx 280^{\circ} \mathrm{C}\right.$, respectively $285^{\circ} \mathrm{C}$ ), the temperature range at which the melting takes place, after which the active substance is subjected to a physical phase transformation within the same temperature range.

Thermal decomposition takes place in two stages; the first of them is determinant. The decomposition process is complex, with three peaks on the DSC curve, the last being exothermic in the case of the active substance (CQ10).

As for the other two pharmaceutical compounds, the thermal decomposition takes place in five stages, some more complexes, with two peaks on the DTG or DSC curves (third and fourth steps respectively).

In principle, the thermal decomposition of the active substance and the pharmaceutical products is similar in terms of heat, but with some differences in the nature and number of processes that take place.

The different thermal behavior of pharmaceutical products is due to their different composition with respect to the excipients present in the molecule and their possible interaction with the active substance.

Fourier transformed infrared spectroscopy (FT-IR)

Along with thermal analysis, FT-IR spectroscopy is an additional technique to investigate the possible drug-drug interaction and to confirm the results of the thermal analysis. This is one of the most attractive methods of analyzing pharmaceuticals because it is the most appropriate method of non-destructive spectroscopy. The emergence or disappearances of new absorption bands, their broadening or bandwidth alteration are the main observations (characteristics) to obtain the desired results.
The FT-IR spectra are presented in figure 6 and the main absorption bands are summarized in table 2 .

The main differences resulting from comparing the spectrum of CQ10 with the spectra of P2, P3 and P1 are presented below, as follow:

-the occurrence, broadening and increase of the bandwidth in the region $3500-3200 \mathrm{~cm}^{-1}$ attributed to the $\mathrm{OH}$ group present in water or excipients (microcrystalline cellulose, methylcellulose, lactose monohydrate, etc.) present in $\mathrm{P} 2$ and $\mathrm{P} 1$;

-the presence of the absorption band at $1746 \mathrm{~cm}^{-1}$, characteristic of the $\mathrm{C}=0$ group of excipients (povidone, magnesium stearate, etc.) for $\mathrm{P} 2$ and $\mathrm{P} 3$;

-the normal position of the absorption band characteristic of the carbonyl group $(C=0)$, in this case ranged from $1720 \mathrm{~cm}^{-1}$ to $1647-1610 \mathrm{~cm}^{-1}$ due to conjugation with the benzene ring;

- changing the position and intensity of absorption bands in the range $1450-1000 \mathrm{~cm}^{-1}$;

- disappearance of the absorption bands from $876 \mathrm{~cm}^{-1}$ for $\mathrm{P} 3$, from $750 \mathrm{~cm}^{-1}$ for $\mathrm{P} 2$ and $600 \mathrm{~cm}^{-1}$ for $\mathrm{P} 2$ and $\mathrm{P} 3$;

- the appearance of the absorption bands at $671 \mathrm{~cm}^{-1}$ or $550 \mathrm{~cm}^{-1}$ in the case of P1.

Based on these observations, the composition of the studied compounds may be considered to be different, due to the presence of the excipients and their possible interaction with the active substance.

The FT-IR spectra and the wavelengths, at which the characteristic bands appear, allow for easy differentiation of the active substance (CQ10) and its pharmaceutical forms.

\section{$X$-ray diffraction}

In addition to the thermal analysis, one of the most complete and modern methods of analysis, namely FT-IR spectroscopy, which is a qualitative analysis method, was used to study the compounds under analysis, and the Xray powder diffraction (XRPD) a method of qualitative and

\begin{tabular}{|c|c|c|c|c|}
\hline Q10 & P1 & $\mathrm{P} 2$ & P3 & Assignment \\
\hline- & $3524-3182 i$ & $3509-3206 i$ & - & VoH $\left(\right.$ gr. $\left.\mathrm{OH} ; \mathrm{H}_{2} \mathrm{O}\right)$ \\
\hline $\begin{array}{l}2963 \mathrm{i} ; 2943 \mathrm{i} \\
2909 \mathrm{i} ; 2849 \mathrm{i}\end{array}$ & $\begin{array}{l}2965 \mathrm{~m} ; 2940 \mathrm{~m} \\
2905 \mathrm{~m} ; 2851 \mathrm{~m}\end{array}$ & $2924 \mathrm{i} ; 2855 \mathrm{i}$ & $2924 \mathrm{i} ; 2853 \mathrm{i}$ & $\begin{array}{l}v_{\text {arym }} \mathrm{CH}_{3}, \mathrm{CH}_{2} \\
v_{\text {vym }} \mathrm{CH}_{3}, \mathrm{CH}_{2}\end{array}$ \\
\hline- & - & $1746 i$ & $1746 \mathrm{i}$ & $v_{\mathrm{C}=0}$ normal \\
\hline $1647 \mathrm{i} ; 1609 \mathrm{i}$ & $1647 \mathrm{~m} ; 1611 \mathrm{~m}$ & 1649im & $1651 w ; 1611 w$ & $v_{\mathrm{C}=} \mathrm{O}$ conjugated \\
\hline $1449 \mathrm{im} ; 1383 \mathrm{~m}$ & $1447 \mathrm{~m} ; 1383 \mathrm{~m}$ & $1447 \mathrm{~m}$ & $1465 \mathrm{~m} ; 1375 \mathrm{w}$ & $\begin{array}{l}\delta_{\text {axym }} \mathrm{CH}_{3}, \mathrm{CH}_{2}, \mathrm{CH} \\
\delta_{\text {vym }} \mathrm{CH}_{3}, \mathrm{CH}_{2}, \mathrm{CH}\end{array}$ \\
\hline $\begin{array}{c}1287 \mathrm{~m} ; 1263 \mathrm{i} \\
1205 \mathrm{im} ; 1153 \mathrm{~m} \\
1103 \mathrm{~m} ; 1022 \mathrm{mw}\end{array}$ & $\begin{array}{c}1263 \mathrm{~m} \\
1204 \mathrm{~m} ; 1143 \mathrm{im} \\
1096 \mathrm{i} ; 1030 \mathrm{i}\end{array}$ & $\begin{array}{l}1212 \mathrm{~m} \\
1088 \mathrm{mw}\end{array}$ & $\begin{array}{c}1238 \mathrm{~m} ; 1183 \mathrm{im} \\
1099 \mathrm{~m}\end{array}$ & $\begin{array}{c}v_{\text {arym. }} \text { C-O-C } \\
v_{\text {sym }} \text { C-O-C } \\
\text { i.p. } \text { C-H bend (ring) }\end{array}$ \\
\hline $876 \mathrm{~m}$ & $876 \mathrm{mw}$ & $876 \mathrm{~m}$ & - & o.p. C-H bend (ring) \\
\hline $795 \mathrm{~m} ; 748 \mathrm{mw}$ & $775 \mathrm{mw} ; 748 \mathrm{mw}$ & - & $723 \mathrm{mw}$ & o.p. C-H bend (ring) \\
\hline- & $671 \mathrm{mw}$ & - & - & o.p. ring C-H bend \\
\hline $600 \mathrm{mw}$ & $602 \mathrm{mw}$ & - & - & $\begin{array}{l}\text { o.p. benzene } \\
\text { substituted }\end{array}$ \\
\hline- & $550 \mathrm{w}$ & - & - & $\mathrm{V}_{\mathrm{O}=\mathrm{C}-\mathrm{N}}$ (povidone) \\
\hline
\end{tabular}

Table 2

THE MAIN ABSORPTION BANDS $\left(\mathrm{cm}^{-1}\right)$ FOR THE STUDIED COMPOUND

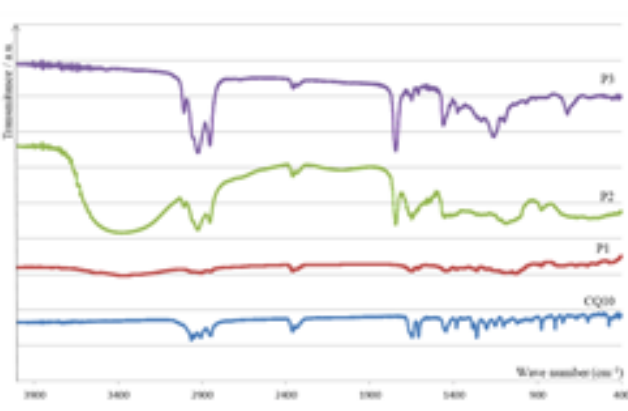

Fig. 6. FT-IR spectra for the studied compounds

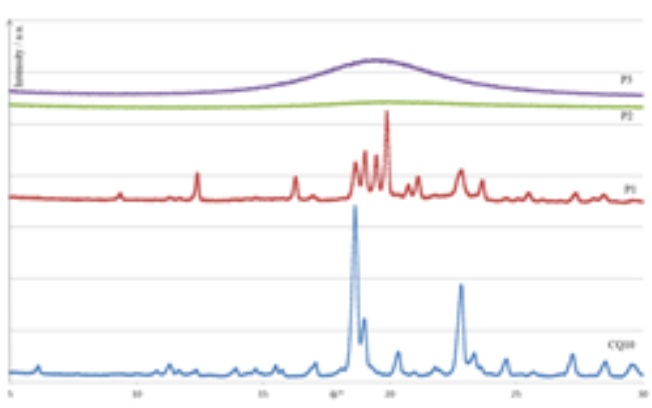

Fig. 7. X-ray diffractogram of the studied compounds 


\begin{tabular}{|c|c|c|c|c|c|}
\hline \multicolumn{2}{|c|}{ CQ10 } & \multicolumn{2}{|c|}{ P1 } & \multicolumn{2}{|c|}{$\mathrm{P} 2$} \\
\hline $2 \theta$ & $1 \%$ & $2 \theta$ & $1 \%$ & $2 \theta$ & $1 \%$ \\
\hline & & 12.40 & 34.66 & & \\
\hline & & 16.29 & 30.41 & & \\
\hline 18,64 & 100,00 & 18.66 & 46.08 & & \\
\hline 19,02 & 35,72 & 19.05 & 57.67 & & \\
\hline & & 19.49 & 53.67 & 19.62 & 100 \\
\hline & & 19.90 & 100.00 & & \\
\hline 20,34 & 17,24 & 20.76 & 22.91 & & \\
\hline & & 21.15 & 31.16 & & \\
\hline 22,83 & 55,13 & 22.79 & 36.59 & & \\
\hline & & 23.68 & 27.16 & & \\
\hline 24,64 & 12,73 & & & & \\
\hline 27,25 & 15,62 & & & & \\
\hline 28,55 & 11,66 & & & & \\
\hline
\end{tabular}

quantitative identification of the crystallinity of substances. The number of specialized articles on the use of this technique is steadily increasing.

Comparison of the diffractograms of the active substance (CQ10) with the diffractograms of the corresponding pharmaceutical compounds (P1, P2 and $\mathrm{P} 3)$ reveals their different composition based on the appearance or disappearance of new lines of high, moderate or weak intensities from the Q10 coenzyme molecule, respectively the change of the intensity of some lines present in the CQ10 molecule.

The X-ray diffraction data for the studied compounds are shown in figure 7 and table 3.

By comparing the data from table 3, respectively, of diffractograms, there are large differences between these compounds, especially between $C Q 10$ and $P 1$, respectively $P 2$ and $P 3$, but also between $C Q 10$ and $P 1$. This is reflected by the disappearance of certain CQ10 lines in P2 and P3, the emergence of new lines for $P 1$, and the change in the intensity of existing lines in CQ10 and P1.

These differences indicate a different composition of the active substance, respectively, of the corresponding pharmaceutical compounds, due to the presence of the excipients and their possible interactions with the active substance.

\section{Conclusions}

The presence of excipients in pharmaceutical products is extremely important, fact which may have a positive or negative influence on the characteristics of the compounds. This influence is due to the possible interaction of the active substance with the excipients present in the drug composition. In this regard, this paper presents a comparative study between coenzyme Q10 - active substance and three of the corresponding pharmaceutical products: P1, P2 and P3. The four compounds were characterized simultaneously by thermal analysis, FT-IR spectroscopy and X-ray pow der diffraction patterns.

Among the methods of analysis mentioned, thermal analysis is the most important method, providing the most complete and accurate information.

To characterize the thermal behavior of the four compounds, the TG / DTG and DSC techniques were used. According to the recorded thermal curves, significant

\begin{tabular}{|l|l|}
\hline \multicolumn{2}{|c|}{ P3 } \\
\hline $2 \theta$ & $1 \%$ \\
\hline & \\
\hline & \\
\hline 19.10 & 100 \\
\hline & \\
\hline & \\
\hline & \\
\hline & \\
\hline & \\
\hline & \\
\hline & \\
\hline & \\
\hline & \\
\hline
\end{tabular}

Table 3

X-RAY DIFFRACTION DATA FOR THE STUDIED COMPOUNDS ditterences were observed between the curves of the active substance (CQ10) and those of the pharmaceutical products, indicating a different composition of these.

Of the thermal methods used, DSC is a retinal technique, often used to identify and control the quality of the active substance in the drug by means of the melting point.

Also, FT-IR spectra and X-ray diffractograms of the two categories of compounds show significant differences.

Based on the results, simultaneous TG / DTG / DSC, FTIR and X-ray analysis is a credible and safe method for accurate control and evaluation in the practice of pure and pharmaceutical compounds.

\section{References}

1. G.P. LITTARRU, P. LAMBRECHTS. OCL 18(2), 2011, p. 76

2. TITA,B., STEFANESCU,M., TITA, D., Rev. Chim. (Bucharest), 62, no.10, 2011, p. 1002

3. A. MOISEI, F. GLIGOR, M. BOJITA, A. CHIS, M. TOTAN, L.A. VONICAGLIGOR, A. CIURBA, Farmacia, 62(6), 2014, p. 1239

4. L. VLASE, D. MUNTEAN, S.C. COZBAC, L. FILIP, Revue Roumaine de Chimie, 59(9), 2014, p. 719

5. J. GU, C.-S. MING, Y. ZHAO, Helvetica Chimica Acta 94(9), Septembrie 2011

6. A.M. JUNCAN, F. FETEA, C. SOCACIU, Eng. Manag. J., 13(1), 2014,

p. 105

7. TITA, B., FULIAS,A., STEFANESCU, M., MARIAN, E., TITA, D., Rev. Chim. (Bucharest), 62, no.2, 2011, p. 216

8. P. GILL, T. T. MOGHADAM, B. RANJ BAR, J ournal of Biomolecular Techniques 21, 2010, p. 167

9. B. TITA, E. MARIAN, A. FULIA', T. JURCA, D. TITA, J. Therm. Anal. Calorim., 112(1), 2013, p. 367

10. F-Q HU, Y ZHANG, Y-Z DU, H YUAN, IntJ Pharm 348, 2008, p. 146 11. FULIAS, A., TITA, B., BANDUR, G. TITA, D., Rev. Chim. (Bucharest), 60, no.10, 2009, p. 1079

12. B. TITA, T. JURCA, D. TITA, J. Therm. Anal. Calorim., 113(1), 2013, p. 291

13. X. MENG, Y. ZU, X. ZHAO, Q. LI, S. JIANG, M. SANG, Pharmazie 67(2), 2012, p. 161

14. D. NAUMANN, C. SCHULTZ, J.BORN, F. ROGGE, H. LABISCHINSKI, Microchimica Acta 94, 1988, p. 379

Manuscript received:21.03.2018 